\title{
Impact of vital signs screening \& clinician prompting on alcohol and tobacco screening and intervention rates: a pre-post intervention comparison
}

\author{
J Paul Seale ${ }^{1 *}$, Sylvia Shellenberger ${ }^{1}$, Mary M Velasquez ${ }^{2}$, John M Boltri ${ }^{1}$, Ike Okosun $^{3}$, Monique Guyinn ${ }^{1}$, \\ Dan Vinson ${ }^{4}$, Monica Cornelius ${ }^{1}$, J Aaron Johnson ${ }^{1}$
}

\begin{abstract}
Background: Though screening and intervention for alcohol and tobacco misuse are effective, primary care screening and intervention rates remain low. Previous studies have increased intervention rates using vital signs screening for tobacco misuse and clinician prompts for screen-positive patients for both alcohol and tobacco misuse. This pilot study's aims were: (1) To determine the feasibility of combined vital signs screening for tobacco and alcohol misuse, (2) To assess the impact of vital signs screening on alcohol and tobacco screening and intervention rates, and (3) To assess the additional impact of tobacco assessment prompts on intervention rates.

Methods: In five outpatient practices, nurses measuring vital signs were trained to routinely ask a single tobacco question, a prescreening question that identified current drinkers, and the single alcohol screening question for current drinkers. After 4-8 weeks, clinicians were trained in tobacco intervention and nurses were trained to give tobacco abusers a tobacco questionnaire which also served as a clinician intervention prompt. Screening and intervention rates were measured using patient exit interviews $(n=622)$ at baseline, during the "screening only" period, and during the tobacco prompting phase. Changes in screening and intervention rates were compared using chi square analyses and test of linear trends. Clinic staff were interviewed regarding patient and staff acceptability. Logistic regression was used to evaluate the impact of nurse screening on clinician intervention, the impact of alcohol intervention on concurrent tobacco intervention, and the impact of tobacco intervention on concurrent alcohol intervention.
\end{abstract}

Results: Alcohol and tobacco screening rates and alcohol intervention rates increased after implementing vital signs screening $(p<.05)$. During the tobacco prompting phase, clinician intervention rates increased significantly for both alcohol $(12.4 \%, p<.001)$ and tobacco $(47.4 \%, p=.042)$. Screening by nurses was associated with clinician advice to reduce alcohol use (OR 13.1; 95\% Cl 6.2-27.6) and tobacco use (OR 2.6; 95\% Cl 1.3-5.2). Acceptability was high with nurses and patients.

Conclusions: Vital signs screening can be incorporated in primary care and increases alcohol screening and intervention rates. Tobacco assessment prompts increase both alcohol and tobacco interventions. These simple interventions show promise for dissemination in primary care settings.

\footnotetext{
* Correspondence: seale.paul@mccg.org

1Department of Family Medicine, Medical Center of Central Georgia and

Mercer University School of Medicine, 3780 Eisenhower Pkwy, Macon, GA 31206, USA
} 


\section{Background}

One in three adults worldwide is a regular smoker, and among these adults, 50\% will die from cigarettes [1]. Cigarette smoking is the most important source of preventable morbidity and mortality in the US, with cost exceeding \$167 billion annually [2]. Almost 30\% of primary care patients use some form of tobacco [3].

Alcohol use is related to a wide range of harms [4]. Approximately one-third of all US adults are involved in alcohol misuse [5], including 14 million adults with alcohol abuse or alcoholism and almost twice that number who are involved in at-risk drinking (for women, more than three drinks per day or seven drinks per week and for men, more than four drinks per day or 14 drinks per week). The cost of alcohol misuse in the U.S. is approximately $\$ 140$ billion annually [6]. Among primary health care patients, 7 to 20 percent engage in alcohol misuse [7]. Alcohol use and tobacco use are often associated, with approximately $50 \%$ of alcohol misusers concurrently using tobacco $[8,9]$. Concurrent tobacco and alcohol use synergistically increase the risk of head and neck and esophageal cancer [10,11]. Binge drinking and alcohol abuse also hinder individuals' efforts to stop smoking [12-14].

Primary care intervention for alcohol and tobacco misuse is effective and reduces morbidity and mortality. Brief advice by primary care clinicians increases quit rates for smokers [15,16] and helps hazardous and harmful drinkers decrease their alcohol consumption [17]. Smoking cessation significantly reduces future cancer risk [18-22]. The U.S. Preventive Services Task Force now recommends screening and office intervention for both tobacco use and problem drinking [23,24]. Combined tobacco and alcohol intervention has the potential to reduce tobacco- and alcohol-related morbidity and cancer risk. Nonetheless, tobacco and alcohol screening and intervention are not consistently performed in most primary care practices. Despite education and training initiatives in alcohol [25-27] and tobacco [1,8,28-30], health care providers screen only $28 \%$ of patients for alcohol misuse [31] and $48 \%$ for tobacco abuse $[1,28,32,33]$.

In an effort to increase screening rates, office protocols have been developed to screen patients before they see their clinicians and prompt clinicians to intervene when screens are positive. Using a vital signs stamp that assesses smoking status as part of nursing vital signs has been shown to increase tobacco cessation rates in three of four studies [34-37]. For alcohol screening, a validated single alcohol screening question (SASQ: "When was the last time you had more than $\mathrm{X}$ drinks in one day?" where $X=4$ for women and 5 for men) has demonstrated acceptable sensitivity and specificity
$[8,38,39]$, however no previous studies have attempted to include this question in nursing vital signs.

Most studies employing reminder systems which prompt primary care clinicians to intervene have resulted in increased clinician intervention rates for tobacco abuse [40-42] and alcohol misuse [43-45], though some studies have showed mixed results [27]. A study by Milch et al [32] combined vital signs screening with nurse administration of a brief tobacco assessment instrument which was then used as a clinician prompt, resulting in increased tobacco interventions by clinicians and higher rates of self-reported smoking cessation. Findings from this single study, however, have not yet been replicated. The purposes of this multi-site study were to: (1) determine the feasibility of combined vital signs screening for tobacco and alcohol misuse, (2) assess the impact of vital signs screening alone on alcohol and tobacco screening and intervention rates, and (3) assess the impact of combined vital signs screening plus use of a tobacco prompt for increasing tobacco interventions.

\section{Methods}

\section{Study Site Recruitment}

This study was approved by the Institutional Review Board of the Medical Center of Central Georgia in Macon, GA, and was conducted from July 2004 to July 2005. A total of 625 patients were eligible and consented to participate in this study.

Interviews were conducted at five Central Georgia family physician offices within the Georgia-Mercer Primary Care Research Network. All clinicians at these offices (physicians, nurse practitioners, and physician assistants) were chosen because of their participation in previous research network studies and were recruited by personal interview. Participation rate was $100 \%$ (no refusals). All five were single specialty offices, and two offices had physician extenders (one nurse practitioner and one physician assistant). Typical of family physicians, all five clinician offices treat the full range of patients: infants to the elderly, with a wide range of problems. The number of patient visits per day ranged from 20 to 60 per clinician. There was a mix of fee for service, HMO, PPO, Medicare and Medicaid patients at each office.

\section{Study Design}

This was a pre-post intervention study conducted in three phases of approximately 50 days each. Prior to integrating alcohol and tobacco vital signs screening into the clinic protocol, baseline alcohol and tobacco screening and intervention rates were collected in Phase I. The effect of each of the study's two interventions was measured in phases II and III. Vital signs screening 
only was implemented in Phase II, followed by vital signs screening plus the tobacco prompt in Phase III. Changes in the following variables were assessed across the study's three phases: alcohol screening by nurses, alcohol screening by clinicians, alcohol screening by nurses and/or clinicians, clinician alcohol intervention, tobacco screening by nurses, tobacco screening by clinicians, tobacco screening by nurses and/or clinicians, and clinician tobacco interventions. For patients reporting tobacco interventions, we also measured the frequency with which clinicians performed any of the seven steps listed on the tobacco intervention prompt (see Figure 1). In each phase, approximately 40 patients per practice completed exit interviews. Prior to baseline measurement, clinicians were informed that the study would involve testing simple interventions that nurses might

Tobacco Assessment Questionnaire

Patient Name: Date:

As part of our efforts to improve your health, we are asking all our patients who smoke to fill out this form at every visit. With this procedure, we hope to belp patients who are ready to quit using tobacco. We understand that you may not be ready to quit at this time, but bope you will take a minute to complete this short questionnaire. There are many new methods to belp you quit using tobacco, so please be sure to ask the physician or nurse practitioner you see today about them.

What kind of tobacco product(s) do you use?
$\square$ Cigarettes
$\square$ Cigars $\square$ Snuff
Chewing tobacco
Other (describe):

On average, how many cigarettes/cigars per day do you smoke?
$\square$ None ever
$\square$ I smoke but not everyday
$\square$ 1-10
$\square 11-20$
$21-30$
More than 30

If you use a form of tobacco other than cigarettes or cigars, how many times per day do you use it?
$\square$ Never
$\square$ I don't use everyday
$\square \quad 1-10$
$\square$ 11-20
$\square$ 21-30
$\square$ More than 30

4. In the past year, how many times have you quit smoking/using for at least 24 hours?

5. Are you seriously considering quitting smoking/using?
$\square$ Yes, within the next 30 days
$\square$ Yes, at some point, but not now
$\square$ Yes, within the next 6 months
$\square$ No, not thinking of quitting

6. How important is it to you to quit smoking/using?
$\square$ Not Important
$\square$ A little
$\square$ Very Important

7. How confident are you that you can quit smoking/using?
$\square$ Not Confident
$\square$ Somewhat Confident
Very confident

8. Do you currently live with someone who smokes?

$\square$ No

$\square$ Yes

Stop Here. Please give this form to the physician or nurse practitioner you see today. Please do not fill out information listed below this line. To be completed by clinician.

\section{Action Steps Completed}

$\square$ Not Ready to Quit (check all that apply)

$\square$ Advised patient to quit

Asked patient what would motivate them to quit

■ Provided educational pamphlet

Provided Quit Line No. 1-877-270-STOP
Ready to Quit (check all that apply)

$\square$ Advised patient to quit

- Counseled patient - discussed barriers to quitting and lessons learned from prior quit attempts

$\square$ Set quit date:

$\square$ Prescribed medication:

$\square$ Arranged follow-up: / 1

$\square$ Referred to smoking cessation program

口 Provided educational pamphlet

Figure 1 Tobacco Assessment Questionnaire. 
perform as part of patient vital signs that might increase tobacco and alcohol screening and intervention. Clinicians were not informed in advance of patient interview days but were often aware when the interviewer was present. In Phase II, which assessed the impact of including alcohol and tobacco screening questions in the nursing vital signs, screening was performed using three questions. The first assessed tobacco use. The second question ("Have you had more than six alcoholic drinks in the past year?") identified patients who were current drinkers. The third question, the SASQ was administered only to patients identified as current drinkers. A vital signs "stamp" was created which could be used to stamp these three questions onto the vital signs portion of the patient's chart (see Figure 2). A fifteenminute orientation session was conducted to orient clinicians to the project procedures and train nurses to ask the three questions as part of nursing vital signs. Procedures were modified for two clinics with electronic medical records which used templates that could not easily be modified to include the screening questions as part of nursing vital signs. In one clinic, the screening questions were printed on sheets of paper and placed in each examining room on clipboards. Nurses were instructed to ask the questions when they placed patients in the room. In the other clinic, the questions were stamped on the paper where nurses routinely recorded each patient's vital signs and left them in the exam room for the physician. Clinicians were informed that positive screens included any tobacco use or drinking more than four (for females) or five drinks (for males) on any day in the past three months, and were encouraged to talk with patients about modifying these habits. In Phase III, vital signs screening continued, and nurses were asked to give a tobacco assessment instrument, adapted from Milch et al [32], to all patients reporting tobacco use (see Figure 1), ask them to complete it and give it to their clinician. All clinicians also received one hour of tobacco intervention training using the steps of the Agency for Healthcare Research and Quality's Clinician's Guide [46]. No specific training was provided regarding further alcohol assessment or brief intervention.

The feasibility of vital signs screening was assessed by interviewing nurses and clinicians and by observation of nurses and clinician behavior by two project investigators (JPS and MG) during Phases II and III at each clinic. The impact of the Phase II and III interventions on alcohol screening and intervention rates was assessed via patient exit interviews.

\section{Patient Recruitment and Eligibility Criteria}

In order to monitor clinic screening and intervention rates, patients were recruited in clinic waiting areas and written informed consent was obtained. Each male patient and every other female patient was invited to participate. Patients first completed a four-question written health habits questionnaire regarding weight, consumption of saturated fats, tobacco use, and alcohol use. English-speaking patients who had consumed at least six alcoholic drinks in the past year and had not already been interviewed for this study met inclusion criteria for the study and were asked to return for an interview after seeing their primary care clinician.

\section{Measures}

The exit interview included demographic information including ethnicity, which was recorded based on patients' self-report. The interview also included the Diagnostic Interview Schedule for alcohol use disorders [47] and a 29-day alcohol Timeline Followback Interview [48]. Alcohol screening was defined as an affirmative answer to the question, "Today, did the nurse who took your blood pressure ask you about your alcohol

Health Habits Screen

\begin{tabular}{|l|c|c|c|}
\hline Tobacco Use: (circle one) & Current & Former & Never \\
\hline $\begin{array}{l}\text { More than 6 total alcoholic } \\
\text { drinks in the entire past year? } \\
\text { (circle answer) }\end{array}$ & Yes & No & \\
\hline $\begin{array}{l}\text { Last time you drank more than } \\
4 \text { or } 5 \text { drinks on one occasion? } \\
\text { (Use } 4 \text { for women and 5 for } \\
\text { men; positive screen if less } \\
\text { than } 3 \text { months) }\end{array}$ & $<3$ months & $>3$ months & Never \\
\hline
\end{tabular}

Figure 2 Health Habits Stamp for Vital Signs Screening 
use?" Alcohol intervention was defined as an affirmative answer to the question, "Today, did the doctor discuss cutting down or stopping your alcohol use?" Similarly worded questions were used to define tobacco use and intervention. Patients who reported being advised to reduce their tobacco use were asked whether the clinician had encouraged them to set a quit date, discussed possible use of pharmacotherapy, given them a smoking cessation handout, or given them information regarding tobacco cessation programs or telephone counseling services.

To determine the percentage of patients who should receive an intervention we calculated the prevalence of alcohol misuse and tobacco abuse using exit interview responses. Alcohol misuse was defined as presence of a DSM-IV [49] alcohol use disorder or at-risk drinking, defined using NIAAA criteria of more than three drinks in a day or seven drinks in a week for women and more than four drinks in a day or 14 drinks in a week for men [50]. Tobacco abuse was defined as any selfreported tobacco use. All patients with alcohol misuse or tobacco abuse were considered as appropriate patients for clinician interventions.

\section{Statistical Analyses}

Statistical programs that are available in SPSS for Windows (version 14.0) were used for analysis [51]. Ethnic differences in age stratified by gender were determined using independent $\mathrm{t}$-tests. Ethnic specific rates for alcohol misuse and tobacco abuse were also stratified by gender, and differences in rates were determined using chi-square tests. Changes in screening and intervention rates across study phases were determined using tests of linear trends. Pair differences in screening rates between individual study phases were measured using chi-square tests.

To assess the odds of alcohol and tobacco interventions that were associated with nurse screening (independent variable), we fitted both univariate and multivariate logistic regression models using alcohol intervention and tobacco intervention as dependent variables. We compared odds ratios of alcohol intervention and tobacco intervention that were associated with nurse screening as part of vital signs. To investigate whether offering tobacco advice was associated with offering alcohol advice and vice versa, we also fitted univariate and multivariate logistic regression models in which first alcohol advice, then tobacco advice was used as the dependent variable. In all multivariate analyses, statistical adjustments were made for patient age, gender and ethnicity. The customary p-values of $<0.05$ and 95\% confidence intervals were used to indicate statistical significance.

\section{Results}

Vital signs screening was successfully implemented during a two-month period at all clinics. Although some nursing staff expressed concerns about asking all patients about the sensitive subject of alcohol prior to startup, these concerns dissipated during the first week as they quickly adapted to talking with patients about their tobacco and alcohol use. After implementation, nurses reported that patients readily accepted the vital signs screening as a part of their visit and that most answered questions freely, with few questions or objections. Two clinics with electronic medical records were unable to insert the alcohol and drug questions into their vital signs templates and collected this information using paper sheets. This was problematic in one clinic, as this created a new procedure which required nurses to remember to pick up a clipboard and ask the screening questions. In the other clinic, fewer problems were experienced: the receptionist stamped the vital signs questions onto the paper where nurses routinely recorded vital signs, thereby integrating the new questions into the existing vital signs procedure.

A total of 622 patients $(99.5 \%$ of patients who consented to participate) provided complete answers to all questions. Approximately 120 patients were recruited from each of the participating five primary care practices. Subject refusal rate, measured during the final month of the study, was $17.5 \%$.

Of the study participants, $378(60.7 \%)$ were white and 238 (38.2\%) were African American. Six (1\%) were of other races. Mean (SD) age was 40.4 (12.8) years (median $=40)$ for women and 42.1 (13.7) years (median = 41) for men. Age and gender distribution of subjects is shown in Table 1. Among men, more whites than African Americans met diagnostic criteria for alcohol misuse $(\mathrm{p}<.05)$, however tobacco abuse rates showed no significant differences. There were no statistically significant ethnic differences in rates of alcohol misuse or tobacco abuse among women.

Low rates of alcohol screening were reported during the baseline period for both nurses alone and for nurses and clinicians combined (9.5 and $14.7 \%$ of patients, respectively; see Table 2). Both these rates increased significantly after implementing vital signs screening (38.1\% and $40.5 \%$, respectively) in Phase II, then plateaued in Phase III, with overall screening rates remaining near 40\%. Alcohol screening and alcohol intervention by clinicians increased modestly but significantly across all phases $(p<.001)$. Changes in tobacco screening rates followed a similar pattern to those observed with alcohol. Tobacco screening rates for nurses alone and for nurses and clinicians combined increased significantly from baseline $(20.4 \%$ and $28.0 \%$, 
Table 1 Characteristics of Study Population

\begin{tabular}{|c|c|c|c|c|c|c|}
\hline & \multicolumn{3}{|c|}{ Men } & \multicolumn{3}{|c|}{ Women } \\
\hline & $\begin{array}{l}\text { White } \\
(n=189)\end{array}$ & $\begin{array}{l}\text { Black } \\
(n=92)\end{array}$ & $p$ & $\begin{array}{l}\text { White } \\
(n=189)\end{array}$ & $\begin{array}{l}\text { Black } \\
(n=146)\end{array}$ & $p$ \\
\hline \multicolumn{7}{|l|}{ Age, in years } \\
\hline Mean (SD) & $42.7(14.3)$ & $41.0(12.6)$ & .388 & $40.4(13.5)$ & $40.5(11.8)$ & .992 \\
\hline Median & 42 & 41.5 & & 40 & 41 & \\
\hline Alcohol misuse & $45.2 \%$ & $31.5 \%$ & .029 & $29.6 \%$ & $30.8 \%$ & .814 \\
\hline Tobacco abuse & $41.8 \%$ & $33.0 \%$ & .156 & $39.2 \%$ & $37.7 \%$ & .782 \\
\hline
\end{tabular}

Notes: Alcohol misuse is defined as at-risk drinking (consumption of more than 3 drinks in 1 day or 7 in 1 week for women, and more than 4 in 1 day or 14 in 1 week for men) and/or presence of a DSM-4 alcohol-use disorder (alcohol abuse and/or alcohol dependence).

Table 2 Changes in Alcohol and Tobacco Screening and Intervention Rates by Study Phases (\%)

\begin{tabular}{|c|c|c|c|c|}
\hline & $\begin{array}{l}\text { Phase I } \\
(n=211)\end{array}$ & $\begin{array}{l}\text { Phase II } \\
(n=210)\end{array}$ & $\begin{array}{l}\text { Phase III } \\
(n=201)\end{array}$ & $p$ \\
\hline \multicolumn{5}{|l|}{ Alcohol Screening and Intervention Rates } \\
\hline Screening by Nurses & $9.5^{\mathrm{a}}$ & $38.1^{\mathrm{b}}$ & $32.3^{c}$ & .018 \\
\hline Screening by Clinicians & $9.5^{\mathrm{a}}$ & $13.4^{\mathrm{b}}$ & $21.9^{c}$ & $<.001$ \\
\hline Any Screening (Nurses or Clinicians) & $14.7^{\mathrm{a}}$ & $40.5^{\mathrm{b}}$ & $37.8^{\mathrm{c}}$ & .041 \\
\hline Clinician Alcohol Interventions & $3.8^{\mathrm{a}}$ & $6.7^{\mathrm{b}}$ & $12.4^{\mathrm{c}}$ & $<.001$ \\
\hline \multicolumn{5}{|l|}{ Tobacco Screening Rates } \\
\hline Screening by Nurses & $20.4^{\mathrm{a}}$ & $44.8^{\mathrm{b}}$ & $41.3^{c}$ & .081 \\
\hline Screening by Clinicians & 18.5 & 18.1 & 26.0 & .121 \\
\hline Any Screening (Nurses or Clinicians) & $28.0^{\mathrm{a}}$ & $49.5^{\mathrm{b}}$ & $49.0^{b}$ & .371 \\
\hline Tobacco Intervention Rates & $(n=87)$ & $(n=76)$ & $(n=76)$ & \\
\hline Clinician advice to quit & $32.2^{\mathrm{a}}$ & $30.3^{b}$ & $47.4^{c}$ & .042 \\
\hline \multicolumn{5}{|l|}{$\underline{\text { Specific Tobacco Quit Steps }}$} \\
\hline Asked what would motivate patient to quit & 14.3 & 17.6 & 25.0 & .021 \\
\hline Gave patient a pamphlet & 9.1 & 9.5 & 15.4 & .017 \\
\hline Discussed lessons learned from past attempts & 7.9 & 6.8 & 9.2 & .421 \\
\hline Discussed setting a date to quit & 3.9 & 8.1 & 10.8 & .029 \\
\hline Discussed nicotine products or other meds & $9.2^{\mathrm{a}}$ & $16.2^{\mathrm{b}}$ & $24.2^{c}$ & $<.001$ \\
\hline Prescribed bupropion or a nicotine product & $3.9^{\mathrm{a}}$ & $5.4^{\mathrm{b}}$ & $12.1^{\mathrm{c}}$ & $<.001$ \\
\hline Gave info about Tobacco Quit Line & 5.3 & 1.4 & 6.1 & .711 \\
\hline Referred to a smoking cessation program & 2.6 & 2.7 & 3.0 & .052 \\
\hline
\end{tabular}

Values with different superscripts differ from each other at $p<.05$ on pairwise comparison; p-values listed in the table arefrom test of linear trends across study phases

respectively) to Phase II ( $44.8 \%$ and $49.5 \%$, respectively), then plateaued, with overall screening rates remaining near 50\%. Interestingly, tobacco intervention rates by clinicians ("clinician advice to quit") showed no increase after implementation of vital signs screening alone (Phase II), then increased significantly with the addition of clinician prompting in Phase III to $47.4 \%(\mathrm{p}=.042)$. Statistical analysis also revealed significant increases across study phases in three individual quit steps (asking patients what would motivate them to quit, giving pamphlets, and discussions about quit dates) and highly significant increases in two steps: discussing quit medications and prescribing quit medications.
Logistic regression analysis demonstrated that nurse screening significantly increased the odds of alcohol intervention, both before adjusting for sociodemographic variables (odds ratio [OR] 12.9, 95\% CI: 6.3 - 26.7) and after adjusting (OR 13.1, 95\% CI 6.2-27.6). Nurse screening also significantly improved the odds of tobacco intervention both before (OR 2.1, 95\% CI 1.15.9 ) and after adjusting for demographic variables (OR 2.6, 95\% CI: 1.3 - 5.2). Giving tobacco advice was associated with increased odds of giving alcohol advice in both univariate (OR 6.8, 95\% CI 2.56-17.8) and multivariate (OR 7.4; 95\% CI 2.8-20.1) analyses. Similarly, giving alcohol advice was also associated with increased 
odds of giving tobacco advice both before (OR 6.89: 95\% CI 3.14-15.15) and after adjusting for age, gender and ethnicity (OR 7.47: 95\% CI 3.32-16.79).

\section{Discussion}

Previous primary care studies have used health screening surveys to assess alcohol and tobacco use [52-54], but the current study is one of the first to incorporate screening for both alcohol and tobacco as part of the vital signs. Screening was accomplished using the SASQ [39], which was easily included in the brief nursing encounter used for vital signs measurement. The threequestion screening system designed for this study proved to be acceptable to nurses, clinicians and patients and resulted in significant increases in alcohol and tobacco screening. Although universal screening was not achieved, alcohol screening rates were similar to the $44-50 \%$ range seen in previous multi-site studies designed to increase alcohol screening in primary care $[44,45,55]$. Results from Phase II of this study demonstrated modest but significant increases in clinician interventions for alcohol but not for tobacco from vital signs screening alone. Our findings are similar to those of Piper et al [37], who found no increase in tobacco intervention rates from vital signs screening for tobacco alone.

This study's more intensive intervention, the addition of a previously-studied tobacco assessment instrument which was also used as a clinician prompt, further improved rates of clinician tobacco cessation advice. Clinician prompts have previously been shown to increase clinician interventions with other health habits such as alcohol misuse $[44,45]$. Our study confirms previous findings of Milch et al [32] regarding the effectiveness of a tobacco prompt in increasing tobacco intervention rates. In this study, clinician cessation advice rates attained with use of the prompt $(47 \%)$ were equal to those found in Milch's study. There were also significant increases in multiple tobacco cessation counseling steps advocated in the steps of the Agency for Healthcare Research and Quality's Clinician's Guide [46] such as setting a quit date and exploring patients' motivation for quitting, indicating that clinicians went beyond simple brief advice. The most significant increases were seen in clinicians' discussing and prescribing quit products, which have been proven to increase patient abstinence rates [56].

This study addresses an important current need in primary care: the development of efficient methods for addressing multiple health risk behaviors in a single visit $[57,58]$. Existing research indicates that physicians limit the preventive services they offer due to time constraints and the high number of competing demands encountered during a single office visit $[59,60]$. Physicians also report a lack of confidence in their ability to screen and provide brief advice [61]. A somewhat surprising finding of this study was the fact that vital signs screening for both tobacco and alcohol misuse, followed by clinician prompts for tobacco abuse only, resulted in increases in both alcohol and tobacco interventions. Despite the time constraints, clinicians in this study who dedicated time to tobacco assessment and counseling were also more likely to perform alcohol interventions. This finding suggests that clinicians providing advice to change one lifestyle behavior may find it easier to address a second behavior. Starting with tobacco use as the target behavior might also increase the physician's confidence in providing screening and advice for alcohol misuse. Further study is needed to explore the link between advice for these two behaviors and perhaps better utilize tobacco cessation encounters as an opportunity to increase clinician alcohol intervention rates.

\section{Limitations}

This study, performed in five single physician practices in the southeastern U.S., may not be representative of other areas of the U.S. However, two strengths of the study are the ethnic diversity of the patient population studied and the involvement of multiple practice sites. Data regarding tobacco screening and intervention were collected only on current drinkers and may not be representative of all tobacco users. Lack of blinding physicians to the presence of the patient interviewer may have influenced their clinical behavior. This study, which was designed to assess practice change behavior, did not assess the impact of clinician interventions on patients' subsequent alcohol and tobacco use or solicit patient feedback regarding the vital sign screening process.

\section{Conclusions}

This study demonstrates that vital signs screening is a simple, efficient and well-accepted method for conducting alcohol and tobacco screening in primary care, and that this intervention, when combined with clinician prompting, increases alcohol and tobacco screening and intervention rates. Importantly, the tobacco assessment prompts in this study increased both alcohol and tobacco interventions. While this simple, lowcost intervention resulted in modest but significant increases, future research should explore interventions which would further increase these rates. Techniques which have been utilized in other studies include emphasizing the link between alcohol misuse and biomedical consequences such as hypertension [62] or abnormal laboratory tests [63], academic detailing [64], and use of a more complex systems-based quality improvement intervention approach [65]. Future 
studies might also include training in alcohol intervention, which has been shown to increase clinician confidence in performing brief intervention [66-69], and test use of a combined sheet with both tobacco and alcohol brief advice steps, in order to improve translation of effective intervention strategies for alcohol and tobacco in primary care.

\section{Acknowledgements}

This study was supported by a grant from the Medcen Foundation, Macon, Georgia. The authors are grateful for the assistance of the following clinicians who participated in the study: Freddy Gaton, MD, W. Steven Wilson, MD, Michael Greene, MD, Richard Culp, MD, Cornell Peters, MD, Sharny Singh, PAC, and Layne B. Williamson, FNP.

\section{Author details}

'Department of Family Medicine, Medical Center of Central Georgia and Mercer University School of Medicine, 3780 Eisenhower Pkwy, Macon, GA 31206, USA. '2 School of Social Work, University of Texas-Austin, Austin, TX, USA. Institute of Public Health, Georgia State University, Atlanta, GA 30302, USA. ${ }^{4}$ Department of Family and Community Medicine, University of Missouri-Columbia, Columbia, MO 65212, USA.

\section{Authors' contributions}

JPS is the corresponding author and created the study design, methods, analysis and participated in manuscript preparation. SS participated in the creation of the study design, analysis, discussion and manuscript preparation. MMV participated in the creation of the analysis, discussion and manuscript preparation. JMB participated in the creation of the study design, discussion and manuscript preparation. 10 participated in statistical analysis, conclusions and manuscript preparation. MG participated in data collection, analysis and discussion. DV participated in statistical analysis, discussion and conclusions. MC participated in data collection, statistical analysis, and discussion. JAJ participated in statistical analysis, discussion and conclusions. All authors have read and approved the final manuscript.

\section{Competing interests}

The authors declare that they have no competing interests.

Received: 12 August 2009 Accepted: 5 March 2010

Published: 5 March 2010

\section{References}

1. Anderson J, Jané-Llopis E: How can we increase the involvement of primary health care in the treatment of tobacco dependence? A metaanalysis. Addiction 2004, 99(3):299-312.

2. Centers for Disease Control and Prevention (CDC): Annual smokingattributable mortality, years of potential life lost, and productivity losses-United States, 1997-2001. Morb Mortal Wkly Rep 2005, 54(25):625-8.

3. Seale JP, Davis-Smith M, Okosun IS: Ethnic and gender differences in lifestyle risk factors in a bi-ethnic primary care sample: prevalence and clinical implications. Ethnicity and Disease 2006, 16(2):460-467.

4. World Health Organization Global Status Report on Alcohol 2004. [http:// www.who.int/substance_abuse/publications/ global_status_report_2004_overview.pdf].

5. Saitz R: Clinical practice: unhealthy alcohol use. N Eng/ J Med 2005, 352(6):596-607.

6. Gmel G, Rehm J: Harmful alcohol use. Alcohol Res HIth 2003, 27:52-62

7. Fiellin DA, Reid MC, O'Connor PG: Screening for alcohol problems in primary care: a systematic review. Arch Intern Med 2000, 160(7):1977-89.

8. Seale JP, Boltri JM, Shellenberger S, Velasquez MM, Cornelius M, Guyinn M, Okosun I, Sumner H: Primary Care Validation of a single screening question for drinkers. J Stud Alcohol 2006, 67(5):778-84.

9. National Institute on Alcohol Abuse and Alcoholism: 2001-2002 National Epidemiologic Survey on Alcohol and Related Conditions.[http://aspe.hhs. gov/hsp/06/Catalog-Al-AN-NA/NESARC.htm].

10. Sturgis EM, Wei Q, Spitz MR: Descriptive epidemiology and risk factors for head and neck cancer. Semin Oncol 2004, 31(6):726-33.
11. Zeka A, Gore R, Kriebel D: Effects of alcohol and tobacco on aerodigestive cancer risks: a meta-regression analysis. Cancer Causes Control 2003, 14(9):897-906

12. Humfleet $G$, Munoz R, Sees $K$, Reus V, Hall S: History of alcohol or drug problems, current use of alcohol or marijuana, and success in quitting smoking. Addict Behav 1999, 24(1):149-54.

13. Hays JT, Schroeder DR, Offord KP, Croghan IT, Patten CA, Hurt RD, Jorenby DE, Fiore MC: Response to nicotine dependence treatment in smokers with current and past alcohol problems. Ann Behav Med 1999, 21(3):244-50.

14. Dawson DA: Drinking as a risk factor for sustained smoking. Drug Alcohol Depend 2000, 59(3):235-49.

15. Silagy C, Stead LF: Physician advice for smoking cessation. Cochrane Database Syst Rev 2001, , 2: CD000165, Review. Update in: Cochrane Database Syst Rev. 2004,(4):CD000165.

16. Katz DA, Muehlenbruch DR, Brown RB, Fiore MC, Baker TB, AHRQ Smoking Cessation Guideline Study Group: Effectiveness of a clinic-based strategy for implementing the AHRQ Smoking Cessation Guideline in primary care. Prev Med 2002, 35(3):293-301.

17. Moyer A, Finney JW, Swearingen CE, Vergun P: Brief interventions for alcohol problems: a meta-analytic review of controlled investigations in treatment-seeking and non-treatment-seeking populations. Addiction 2002, 97(3):279-92

18. Crispo A, Brennan $P$, Jöckel KH, Schaffrath-Rosario A, Wichmann HE, Nyberg F, Simonato L, Merletti F, Fora Stiere F, Boffetta P, Darby S: The cumulative risk of lung cancer among current, ex- and never-smokers in European men. Br J Cancer 2004, 91(7):1280-1286.

19. Ebbert JO, Yang P, Vachon CM, Vierkant RA, Cerhan JR, Folsom AR, Sellers TA: Lung cancer risk reduction after smoking cessation: observations from a prospective cohort of women. J Clin Oncol 2003, 21(5):921-6.

20. Peto R, Darby S, Deo H, Silcocks P, Whitley E, Doll R: Smoking, smoking cessation, and lung cancer in the UK since 1950: combination of national statistics with two case-control studies. BMJ 2000, 321(7257):323-9.

21. Cheng KK, Duffy SW, Day NE, Lam TH, Chung SF, Badrinath P: Stopping drinking and risk of oesophageal cancer. BMJ 1995, 310(6987):1094-7.

22. Franceschi S, Levi F, Dal Maso L, Talamini R, Conti E, Negri E, LaVecchia C: Cessation of alcohol drinking and risk of cancer of the oral cavity and pharynx. Int J Cancer 2000, 85(6):787-90.

23. U.S. Preventive Services Task Force: Counseling to Prevent Tobacco Use. [http://www.ahrq.gov/clinic/uspstf/uspstbac.htm].

24. U.S. Preventive Services Task Force: Screening for Alcohol Misuse. [http:// www.ahrq.gov/clinic/uspstf/uspsdrin.htm].

25. Brown RL, Marcus MT, Straussner SLA, Graham AV, Madden T, Schoener E, Henry R: Project mainstream's first fellowship cohort: pilot test of a national dissemination model to enhance substance abuse curriculum at health professions schools. Hlth Edu J 2006, 65(3):252-66.

26. Eagles JM, Calder SA, Nicoll KS, Sclare PD: Using simulated patients in education about alcohol misuse. Acad Med 2001, 76:395.

27. Saitz R, Horton NJ, Sullivan LM, Moskowitz MA, Samet JH: Addressing alcohol problems in primary care: a cluster randomized, controlled trial of a systems intervention. The screening and intervention in primary care (SIP) study. Ann Intern Med 2003, 138(5):372-82.

28. Cornuz J, Humair JP, Seematter L, Stoianov R, van Melle G, Stalder H, Pécoud A: Efficacy of resident training in smoking cessation: a randomized, controlled trial of a program based on application of behavioral theory and practice with standardized patients. Ann Intern Med 2002, 136(6):429-37.

29. Young JM, Ward J: Can distance learning improve smoking cessation advice in family practice? A randomized trial. $J$ Contin Educ Health Prof 2002, 22(2):84-93.

30. Young JM, D'Este, Ward JE: Improving family physicians' use of evidencebased smoking cessation strategies: a cluster randomization trial. Prev Med 2002, 35(6):572-83.

31. Edlund MJ, Unutzer J, Wells KB: Clinician screening and treatment of alcohol, drug, and mental problems in primary care: results from healthcare for communities. Med Care 2004, 42(12):1158-66.

32. Milch CE, Edmunson JM, Beshansky JR, Griffith JL, Selker HP: Smoking cessation in primary care: a clinical effectiveness trial of two simple interventions. Prev Med 2004, 38(3):284-94. 
33. Katz DA, Muehlenbruch DR, Brown RB, Fiore MC, Baker TB, AHRQ Smoking Cessation Guideline Study Group: Effectiveness of a clinic-based strategy for implementing the AHRQ smoking cessation guideline in primary care. Prev Med 2002, 35:293-301.

34. Fiore MC, Jorenby DE, Schensky AE, Smith SS, Bauer RR, Baker TB: Smoking status as the new vital sign: effect on assessment and intervention in patients who smoke. Mayo Clin Proc 1995, 70(3):209-13.

35. Ahluwalia JS, Gibson CA, Kenney RE, Wallace DD, Resnicow K: Smoking status as a vital sign. J Gen Intern Med 1999, 14:402-408.

36. Andrews JO, Tionen MS, Waller JL, Harper RJ: Provider feedback improves adherence with AHCPR Smoking Cessation Guideline. Prev Med 2001, 33:415-421.

37. Piper ME, Fiore MC, Smith SS, Jorenby DE, Wilson JR, Zehner ME, Baker TB: Use of the vital sign stamp as a systematic screening tool to promote smoking cessation. Mayo Clin Proc 2003, 78:716-722

38. Taj N, Devera-Sales A, Vinson DC: Screening for problem drinking: does a single question work? J Fam Pract 1998, 46:328-335.

39. Williams $R$, Vinson DC: Validation of a single screening question for problem drinking. J Fam Pract 2001, 50:307-312

40. Lancaster T, Silagy C, Fowler G: Training health professionals in smoking cessation. Cochrane Database Syst Rev 2000, , 3: CD000214.

41. Etter JF, Rielle JC, Perneger TV: Labeling smokers' charts with a "smoker" sticker: results of a randomized controlled trial among private practitioners. J Gen Intern Med 2000, 15(6):421-4.

42. McEwen A, West R, Preston A: Triggering anti-smoking advice by GPs: mode of action of an intervention stimulating smoking cessation advice by GPs. Patient Educ Couns 2006, 62(1):89-94.

43. Friedmann PD, Rose J, Hayaki J, Ramsey S, Charuvastra A, Dubé C, Herman D, Stein MD: Training primary care clinicians in maintenance care for moderated alcohol use. J Gen Intern Med 2006, 21(12):1269-75.

44. Seale JP, Shellenberger S, Tillery WK, Boltri J, Vogel R, Barton B, McCauley M Implementing alcohol screening and intervention in a family medicine residency clinic. Substance Abuse 2005, 26(1):23-31.

45. Babor TF, Higgins-Biddle JC, Dauser D, Burleson JA, Zarkin GA, Bray J: Brief interventions for at-risk drinking: patient outcomes and costeffectiveness in managed care organizations. Alcohol Alcohol 2006, 41(6):624-31

46. Treating Tobacco Use and Dependence: Clinical Practice Guideline Rockville, MD: U.S. Department of Health and Human Services. Public Health Service [http://www.surgeongeneral.gov/tobacco/ treating_tobacco_use.pdf].

47. Robins LN, Cottler L, Bucholz K, Compton W: Diagnostic Interview Schedule for DSM-IV (DIS-IV) St. Louis, MO: Department of Psychiatry, Washington University School of Medicine 1995

48. Sobell LC, Sobell MB: Timeline follow-back: a technique for assessing selfreported alcohol consumption. Measuring alcohol consumption: psychosocial and biochemical methods Totowa, NJ: Humana PressLitten RZ, Allen JP 1992, 41-72

49. American Psychiatric Association: Diagnostic and Statistical Manual of Mental Disorders Washington, DC: American Psychiatric Association, Fourth 1994

50. National Institute on Alcohol Abuse and Alcoholism: Helping Patients Who Drink Too Much, 2005 Edition. [http://www.niaaa.nih.gov/Publications/ EducationTrainingMaterials/guide.htm]

51. SPSS 14.0 Software and Manual, 2006 Edition. [https://www.spss.com/ software/?source=homepage\&hpzone=nav_bar].

52. Manwell LB, Fleming MF, Johnson K, Barry KL: Tobacco, alcohol, and drug use in a primary care sample: 90-day prevalence and associated factors. J Addict Dis 1998, 17(1):67-81

53. Manwell LB, Ignaczak M, Cxabala JC: Prevalence of tobacco and alcohol use disorders in Polish primary care settings. Eur J Public Health 2002, 12:139-144.

54. Ozer EM, Adams SH, Lustig JL, Gee S, Garber AK, Gardner LR, Rehbein M, Addison L, Irwin CE Jr: Increasing the screening and counseling of adolescents for risky health behaviors: A primary care intervention. Pediatrics 2005, 115(4):960-968.

55. Anderson $P$, Laurant M, Kaner E, Wensing M, Grol R: Engaging general practitioners in the management of hazardous and harmful alcohol consumption: results of a meta-analysis. J Stud Alcohol 2004, 65(2):191-9.

56. Silagy C, Lancaster T, Stead L, Mant D, Fowler G: Nicotine replacement for smoking cessation. Cochrane Database Syst Rev 2004, 3: CD000146.
57. Rollnick S, Mason P, Butler C: Health Behavior Change: A Guide for Practitioners London, Churchill Livingstone 1999.

58. Strecher V, Wang C, Derry H, Wildenhaus K, Johnson C: Tailored interventions for multiple risk behaviors. Health Education Research 2002 17(5):619-626.

59. Yarnall KS, Pollak Kl, Ostbye T, Krause KM, Michener JL: Primary care: is there enough time for prevention? Am J Public Health 2003, 93(4):635-41.

60. Crabtree BF, Miller WL, Tallia AF, Cohen DJ, DiCicco-Bloom B, Mcllvain HE, Aita VA, Scott JG, Gregory PB, Stange KC: Delivery of clinical preventive services in family medicine offices. Ann FamMed 2005, 3:430-435.

61. Friedmann PD, McCullough D, Chin MH, Saitz R: Screening and intervention for alcohol problems. A national survey of primary care physicians and psychiatrists. J Gen Intern Med 2000, 15(2):84-91.

62. Miller PM, Stockdell R, Nemeth L, Feifer C, Jenkins RG, Nietert PJ, Wessell A, Liszka $\mathrm{H}$ : Initial steps taken by nine primary care practices to implement alcohol screening guidelines with hypertensive patients: the AA-TRIP project. Substance Abuse 2006, 27(1/2):61-70

63. Fleming $M$, Brown $R$, Brown D: The efficacy of a brief alcohol intervention combined with \%CDT feedback in patients being treated for type 2 diabetes and/or hypertension. J Stud Alcohol 2004, 65(5):631-7.

64. Funk M, Wutzke S, Kaner E, Anderson P, Pas L, McCormick R, Gual A Barfod S, Saunders J, World Health Organization Brief Intervention Study Group: A multi-country controlled trial of strategies to promote dissemination and implementation of brief alcohol intervention in primary health care: findings of a World Health Organization collaborative study. J Stud Alcohol 2005, 66(3):379-88.

65. Cohen D, McDaniel RR Jr, Crabtree BF, Ruhe MC, Weyer SM, Tallia A, Miller WL, Goodwin MA, Nutting P, Solberg LI, Zyzanski SJ, Jaén CR, Gilchrist $V$, Stange KC: A practice change model for quality improvement in primary care practice. J Healthc Manag 2004, 49(3):155-68.

66. Adams A, Ockene J, Wheeler E, Hurley T: Alcohol counseling: Physicians will do it. J Gen Intern Med 1998, 13:692-698.

67. Richmond RL, G-Novak K, Kehoe L, Calfas G, Mendelsohn CP, Wodak A: Effect of training on general practitioners' use of a brief intervention for excessive drinkers. Aust N Z J Public Health 1998, 22:206-9.

68. Babor TF, Higgins-Biddle JC, Higgins PS, Gassman RA, Gould BE: Training medical providers to conduct alcohol screening and brief interventions. Subst Abus 2004, 25:17-26.

69. Roche AM, Stubbs JM, Sanson-Risher RW, Saunders J: A controlled trial of educational strategies to teach medical students brief intervention skills for alcohol problems. Prev Med 1997, 26:78-85.

\section{Pre-publication history}

The pre-publication history for this paper can be accessed here: [http://www.biomedcentral.com/1471-2296/11/18/prepub]

\section{doi:10.1186/1471-2296-11-18}

Cite this article as: Seale et al: Impact of vital signs screening \& clinician prompting on alcohol and tobacco screening and intervention rates: a pre-post intervention comparison. BMC Family Practice 2010 $11: 18$

\section{Submit your next manuscript to BioMed Central and take full advantage of:}

- Convenient online submission

- Thorough peer review

- No space constraints or color figure charges

- Immediate publication on acceptance

- Inclusion in PubMed, CAS, Scopus and Google Scholar

- Research which is freely available for redistribution 